\title{
A Life-Course View on Ageing Consumers: Old-Age Trajectories and Gender Differences
}

\author{
Matthias Pannhorst ${ }^{1}$ (D) Florian Dost ${ }^{2}$
}

Received: 13 January 2020 / Accepted: 23 February 2021 / Published online: 8 June 2021

(C) The Author(s) 2021

\begin{abstract}
This study presents a dynamic, model-based view of consumers' ageing developments, focused on gender differences, to uncover the pathways and socioeconomic transitions that female and male consumers take through old age. The analysis of longitudinal survey data spanning 15 years uses a latent Markov dynamic cluster model with transitions over time. The resulting life courses allow an exploration of lifestylerelated changes in multiple consumer well-being variables beyond age 50. Substantial well-being differences appear in the ageing paths of men and women. In both cases, a dominant chronological sequence through old age is complemented by less common transitions, rarely associated with advanced age. Although the model does not use chronological age as an independent variable, it outperforms purely agebased, or agecohort-, and period-based models in predicting old-age consumer wellbeing. These results highlight the importance of considering within-cohort diversity when modelling the accompaniments of old age: while some older consumers enjoy active lifestyles, others of similar age succumb to depression and loneliness, rendering age an insufficient predictor of well-being states. In the future, the presented model could be matched with other, even cross-sectional, consumer survey data to help predict various dynamics in the ageing consumer population.
\end{abstract}

Keywords Ageing consumers · Consumer well-being · Gender differences · Life course analysis $\cdot$ Longitudinal methods

Matthias Pannhorst

pannhorst@europa-uni.de

Florian Dost

florian.dost@b-tu.de

1 European University Viadrina, Große Scharrnstr. 59, 15230 Frankfurt (Oder), Germany

2 Brandenburg University of Technology, Institute of Business and Economics,

Erich-Weinert-Straße 1, Cottbus 03046, Germany 


\section{Introduction}

In many developed societies, demographic changes have led to an increased share of people beyond retirement age (Bloom, 2011). At the same time, sustained peaceful economic growth has shifted spending power to consumers aged 50 years and older (Pak \& Kambil, 2006). These joint trends will reach unprecedented heights as the 'baby boomer generation', the biggest and richest post-war age cohort, reaches retirement age. Members of this cohort will enjoy longer life expectancies, higher accumulated wealth, and greater social benefits than previous (and perhaps subsequent) generations. As a consequence, managers, policymakers, and consumer researchers increasingly have to deal with distinct consumer needs of the generation aged 50 and older (Williams \& Page, 2011). Yet while some countries have given the issue a prominent place in their policy agendas, the UK government, for example, appointed a minister for the well-being consequences of advancing age (Walker, 2018), research on older consumers is surprisingly scarce (Kohlbacher \& Hang, 2011; Pak \& Kambil, 2006).

What is particularly interesting when studying older consumers as compared to younger segments is that the shifts in demographic weights and spending power are complemented by increasingly diverse lifestyles: many older consumers pursue fulfilling and autonomous lifestyles, packing their post-retirement schedules with activity and consumption (Bowling \& Dieppe, 2005; Moschis et al., 1997; Thompson \& Thompson, 2009). On the flipside, ageing also takes a natural toll on health and social connections. Often frailty and loneliness ensue with detrimental consequences for wellbeing. Thus, as a group, old-age consumers are likely to exhibit diverging ageing dynamics. This can, for example, translate into different life events happening within the same age cohort, diverse household arrangements coupled with different economic behaviours (Pannhorst \& Dost, 2019), and potentially different life satisfaction scores throughout the old-age years. Moreover, any within-cohort heterogeneity is further exacerbated as women and men tend to age differently and expect different life spans. Taken together, these reasons suggest older consumers' lives are showing many facets and a marked diversity as rich or even surpassing those of youthful twenty- to thirtysomething consumers, who still dominate the thoughts and empirics of consumer and well-being research.

Studying diverse and diverging ageing dynamics and their implications for older consumer well-being is challenging for three reasons. First, changes to a lifestyle and the accompanying changes in well-being can happen abruptly, around single events or transitions; this prevents researchers from using simple linear statistical models of chronological ageing, as these cannot accurately reflect the non-linear patterns in oldage life courses. Second, a relevant heterogeneity within similar age groups (consumers of similar age leading markedly different lives) prevents the use of models that account for abrupt seasonal or between cohort changes; even models that reflect trends, period shocks, and the heterogeneity between cohorts, such as the well-known age, period, cohort (APC) population models used for example in epidemiological or demographic analyses (Rentz et al., 1983), may not adequately reflect diverging lifestyles and strong heterogeneity within age cohorts, because they miss the less common life trajectories which are masked by the dominant majority averages. Third, many variables of interest, such as indicators of well-being, are often only available at a cross-sectional level; modelling diverging life courses, however, requires integrating these cross-sectional 
data with longitudinal data that offer information for ageing dynamics (Butz \& Torrey, 2006; Mayer, 2009).

To address these challenges, we propose a life course-based model of ageing consumers. Life course research assumes that people's trajectories through (advanced) age can be identified by sets of select socioeconomic or other indicators as markers for important life events. Such indicators, e.g. partnership status or income, provide an observable basis of underlying life(style) states, which in turn are indicative for a wealth of other unobserved or latent covariates; changes in the indicators mark significant life events and identify (gerontological) transition processes; (Alwin, 2012; Elder, 1985). In the life course paradigm, it is the transitions between life states that mark the accompaniments of ageing, not chronological age itself. As several life states could exist in parallel, models of life courses should capture the strong heterogeneity in older consumers' modern-society lifestyles better than models that use chronological age to explain age-related changes (Lowsky et al., 2013; Settersten Jr. \& Mayer, 1997). In prior research, life course approaches have disentangled trajectories from early adulthood (Macmillan \& Eliason, 2003) and midlife of U.S. consumers (Du \& Kamakura, 2006). The present research extends this idea to representative data from German old-age consumers, and empirically constructs a life course and ageing model for consumers aged 50 years and older.

Methodologically, we adopt a longitudinal approach and model the life course through old age with a latent Markov model. Latent Markov models cluster individuals into latent states and estimate their transition probabilities between such states over time. We consider this modelling approach conceptually close to the life course notion of life trajectories defined by individual sequences of life events. Noting the strong evidence that gender markedly affects when and how age-related changes occur (Gold et al., 2002; Kryspin-Exner et al., 2011; Macintyre et al., 1996), we estimate two separate models to provide insights into how men and women age differently. Both models provide a set of empirically derived life states and the transition probabilities between states, identifying common or dominant as well as less common pathways of male and female consumers through old age. Our findings show that while dominant pathways through old age follow a chronological trajectory, there are apparent deviations, suggesting diverse pathways between and within life courses of male and female consumers. Interestingly, many of the less common life states encompass a wider range of chronological age compared to most life states in the dominant pathways, suggesting trajectories through old age where lifestyle characteristics are not primarily shaped by age.

Our longitudinal latent Markov life course model provides a framework to investigate old-age consumers' lifestyles and behaviours within and across the diversity of life course trajectories. Many additional variables and measures of interest, for example from cross-sectional surveys, can be linked to the empirically derived life states. Here, we use four different indicators of well-being to demonstrate the predictive accuracy of the proposed life course approach. Specifically, we predict states and changes in household income, life satisfaction, loneliness and depression - all variables of increasing policy and management relevance, where heterogeneity among older consumers may be particularly strong. We benchmark the latent Markov model results against several age-regression models and an age, period, and cohort model to demonstrate the performance of an empirical life course approach. 


\section{Theoretical Background}

Human ageing is a complex phenomenon involving a multitude of changes. No model can capture the ageing process in its entirety but a broad range of approaches seek to capture single aspects of the ageing process, e.g. changes in physical capacity, strategies to counter cognitive decline, or changes in social activity patterns (Crimmins \& Beltrán-Sánchez, 2011; Fry, 1992; Yoon et al., 2009). All these research streams focus on age-related changes, whether they consider the "decline and loss associated with advanced age" (Baltes \& Carstensen, 1996, p. 399) or the prerequisites and challenges for ageing successfully (Bowling \& Iliffe, 2006; Rowe \& Kahn, 1987).

Acknowledging the calls for greater consideration of longitudinal aspects in the social sciences in general and in studies around ageing in particular (Butz \& Torrey, 2006; Moschis, 2012), the so-called life course paradigm offers a framework to examine age-related changes over time. This research idea first received increased attention in sociology in the 1970ies as a means to analyse social transitions (Billari, 2009; Mayer, 2009). With its goal of providing a context-sensitive, dynamic analysis of social arrangements, life course research internalises age as a defining process for individuals, not so much as separate phases that every individual goes through (Baltes \& Mayer, 2001). Later, also consumer research picked up the approach, where especially the work of Moschis brings together old-age research and a life course view (Moschis, 2007; Moschis, 2012).

Despite its popularity, the life course perspective also faces criticism. For example, it may lack a consistent empirical application (Dannefer, 2003). The distinction and terminology to define what constitutes life course research, or not, also remains unclear (Alwin, 2012; Hendricks, 2012). A drawback of early empirical life course studies has been that the definitions and sequences of ageing pathways have seemed largely arbitrary, rather than empirically derived, featuring subjective notions of what defines the "normal" trajectory - as well as zeitgeist-induced changes thereof (Schaninger \& Danko, 1993; Wagner \& Hanna, 1983).

In this study, we address such shortcomings by modelling life states and transitions based on empirical survey data. That way our data defines what ageing trajectories look like and what transitions people go through. The evidence is strong that such changes in life circumstances often go along with behavioural changes (Elder, 1985; Macmillan \& Eliason, 2003) that can have direct implications for marketers, e.g. when people change brand preferences in the wake of a life event (Mathur et al., 2003). Methodologically, we use a latent Markov model to define life states and transitions. Such models have so far been a rare operationalisation of life course research: we know of two studies that apply a Markov model from a sociological perspective (Espenshade, 1986; Macmillan \& Eliason, 2003), and another analysis that takes a marketing standpoint (Du \& Kamakura, 2006). As a complex model, we believe our framework can help advance the general discourse and also theory building in marketing in that it allows to systematically derive and assess ageing pathways for different consumer groups (Burton, 2005).

Once our Markov model has drawn a map of how people move through old age we connect this evidence to different variables of subjective well-being to explore changes in behaviour, attitude and sentiment. Subjective well-being - a long-established concept in the psychological and gerontological sciences that goes back to Wilson (1967) 
and Diener (1984) — has received increased interest among marketers, primarily to explain or predict consumer behaviour and sentiment (Ganglmair-Wooliscroft \& Lawson, 2012; Silvera et al., 2008; Sudbury \& Simcock, 2009). Subjective wellbeing is a broad concept that is comprised of people's positive or negative affects as well as measures of domain-specific and overall life satisfaction (Diener et al., 1999). In brief, it can be defined as a person's positive outlook on their own lives that evokes positive feelings (Pinquart \& Sörensen, 2000). While even Diener et al. (1999) concede that the components of subjective well-being usually correlate strongly, research shows evidence of discriminant validity for each of those constructs (Lucas et al., 1996). For consumer marketing, subjective well-being as a concept becomes relevant as each of its constructs translates into different aspects of emotion and psychology that are central to marketing products to individuals (Bagozzi et al., 1999).

Finally, we model the ageing trajectories separately for men and women, because the genders seem to age 'differently' from both physiological and psychological points of view. It has been found that the physiological processes of ageing affect men and women differently. As an example, the reduction of brain volume with increasing age happens in different parts of the brain for men and women. This in turn leads to distinct expressions of ageing such that, for example, women tend to show deficits in memory functions more regularly than men. The evidence for psychological ageing differences is less conclusive; however, it is assumed that that similar differences exist between men and women: There is evidence, for example, that both genders differ in their coping mechanisms, e.g. with regard to stress responses (Kryspin-Exner et al., 2011). Interestingly, gender as an explaining variable in aging models usually yields better results when combined with other, often social, metrics: Macintyre et al. (1996) find that the phase of the life cycle, operationalized in the form of different age buckets, can help explain gender differences in health status. With increasing age, this interaction of different variables becomes increasingly complex.

Extant research does not always reflect such differences and complexity: Often times it offers overly simplistic but commonly held views, such as the notion that men die earlier than women (Gorman \& Read, 2007) or that men have a shorter span of morbidity (Macintyre et al., 1996). Contemporary research gradually has come to acknowledge the influence of behavioural and social factors on such differences (Perrig-Chiello \& Hutchison, 2010), revealing hypothesized mechanisms that often are extraordinarily complex (Arber \& Cooper, 1999; Macintyre et al., 1996). By focusing on social institutions as potential predictors of change, we seek to affirm that age-related changes are not just a biological or gender outcome of advanced age alone but rather a process in which biological, social, and psychological factors intersect.

\section{Methods}

\section{Approach}

We take a two-step approach to our analysis. In a first step, we empirically derive typical states in the ageing process. In line with the life course paradigm, we define these states by household configurations, as an implicit indicator of different social roles (Elder, 1985; Macmillan \& Eliason, 2003). This step results in a number of life 
states and transition probabilities for the moves between those states over time. These pathways provide a flexible starting point for further inquiries. In a second step, we link the old-age trajectories to variables related to well-being and demonstrate the explanatory power and predictive accuracy of the life course trajectories over simple agebased models and more complex APC-like models.

\section{Latent Markov Model}

The first stage of our analysis is based on a latent Markov model, a longitudinal approach that can depict typical trajectories through old age, using changes in personal life circumstances as markers for the transitions. We conduct this analysis separately for men and women, similar to a multigroup model. A latent Markov model clusters observations on the basis of a defined number of manifest indicators, and it also can model transitions between those clusters over time. It is historically rooted in the hidden Markov models in speech recognition applications; the uses of latent Markov models in the social sciences are more recent (Visser et al., 2009).

Our latent Markov model is given by the probability of a particular response vector $y_{i}$ to the manifest indicators for each of $i=1, \ldots, I$ survey participants:

$$
P\left(y_{i}\right)=\sum_{s_{0}=1}^{S} \cdots \sum_{s_{T}=1}^{S} \mathrm{P}\left(s_{0}\right) \prod_{t=1}^{T} P\left(s_{t} \mid s_{t-1}\right) \prod_{t=1}^{T} \prod_{j=1}^{J} P\left(y_{i t j} \mid s_{t}\right)
$$

The probability of finding a particular response vector thus is the product of observing this vector, given a specific class membership, and a time point weighted by the history of class memberships.

A latent Markov model is composed of three sets of parameters: First, the initial state probabilities $P\left(s_{0}\right)$ describe the probability of entering the sample in a given latent state $s=1, \ldots, S$. Because membership in more than one state at any point in time is not possible, the probabilities sum to 1 , or $\sum_{s_{0}=1}^{S} P\left(s_{0}\right)=1$.

Second, the item response probabilities $P\left(y_{i t} \mid s_{t}\right)$ indicate the probability of participant $i$ responding with $y_{i t j}$ on the manifest indicator $j=1, \ldots, J$ at time $t$, conditional on the latent state at that time. For each categorical indicator variable $j$, there are $\mathrm{y}_{\mathrm{itj}}=1$, $\ldots, \mathrm{L}_{\mathrm{j}}$ response categories. Of those categories, each participant may pick only one response, so the response probabilities sum to 1 for any given $j, s$, and $t$, or $\sum_{y_{t j}=1}^{L_{j}} P\left(y_{i t j}\right.$ $\left.\mid s_{t}\right)=1$, where $y_{t j}$ denotes possible responses at a specific time $t$ to a specific observed indicator $j$. In our model, we assume measurement invariance across time, such that the response probabilities are time homogeneous, and the meaning of the latent states over time remains unchanged. This assumption also supports the identifiability of our model. It is the only parameter restriction we impose. Conditional on the latent state $s_{t}$, the observed indicators are independent of one another, also known as the conditional independence assumption.

Third, the transition probabilities $P\left(s_{t} \mid s_{t-1}\right)$ represent how individuals move across latent states over time; any current state only depends on the state previously occupied, which is known as the first-order Markov assumption. Just like the initial state probabilities, any individual cannot hold more than one state at a time: $\sum_{s_{t}=1}^{S} P\left(s_{t}\right.$ $\left.\mid s_{t-1}\right)=1$. 
The mentioned parameter restriction pertains to the consistent interpretability of the latent states across time points. But this consistency does not apply across the two groups - men and women-we model. Textbook examples usually recommend avoiding such invariance for multigroup settings, for the sake of easy, straightforward interpretability (Collins \& Lanza, 2010), but this restriction is not appropriate for our model, which looks to explain how men and women age differently. That is, we look for instances in which both ageing trajectories and personal circumstances (i.e. item response probabilities) exhibit differences. Those differences certainly require caution when it comes to their interpretation, but restricting the individual living circumstances of men and women to be the same in aggregate would not do justice to reality.

Finally, we apply sampling weights to the Markov model, using a robust two-step estimation algorithm in which the model is estimated first using unweighted parameters, and then the cluster sizes are adjusted for the sampling weights (Vermunt \& Magidson, 2013). To estimate our latent Markov model, we used LatentGOLD 5.0 Advanced (Vermunt \& Magidson, 2013).

\section{Data and Variables}

This study is based on data from a public release of the German Ageing Survey (DEAS), provided by the Research Data Centre of the German Centre of Gerontology (DZA), a longitudinal panel survey representative of the German population over 40 years of age (Engstler \& Schmiade, 2013). The survey currently consists of four waves, from 1996, 2002, 2008, and 2011, containing more than 22,000 interviews with nearly 15,000 people. It contains a broad range of interdisciplinary variables, though with a focus on the social environment and quality of life for people of advanced ages.

The unit of study is the individual rather than households or greater aggregates, as is common in most longitudinal research of older populations. With this level, we can make distinctions on the basis of indicators such as gender or individual health, which are often obscured in studies of households in their entirety or a household head as a proxy (Wagner \& Hanna, 1983).

To provide sufficient data integrity for the latent Markov model we did not use the entire initial sample. For one, we selected only respondents who participated in at least three of the four survey waves, to ensure our model is based on an adequate number of real transitions. Second, we imposed a cut-off age of 50 years, to ensure that retirement as a transformative event would be included in our sample (Moen, 2003; Reitzes \& Mutran, 2004); this is supported by our data, in which we find that the number of retirees increases greatly among people older than 55 years. The total sample for our latent Markov model thus includes 4232 interviews with 1299 people, with 964 missing records representing interviews comprising only three waves, not all four. Of the 1299 interviewees, $608(47 \%)$ are women and 691 (53\%) are men. In the second step of our analysis we revert back to the full sample of people aged 50 years and older using a scoring technique.

As manifest indicators to define and describe the resulting latent states, we use four variables: marital status, employment status, partner employment status, and parenthood. Together, they can provide information about various transitions in older age. As objectively measurable, major social institutions in Western societies, these variables also have been used in the few comparable previous analyses that focus on mid-life (Du 
\& Kamakura, 2006; Macmillan \& Eliason, 2003). The concise set of indicator variables also yields more homogeneous, well-separated latent states in the model, which aids interpretability. Each indicator variable consists of several nominal categories, as we detail subsequently, in Table 1.

\section{Results of Step 1: Life States}

\section{Model Selection}

To select the model that best fits our data, we estimate versions with 5 to 15 latent states for each gender. The contingency tables of the observed responses to our indicators are sparse: Of 180 possible response patterns, only 70 (plus 20 different patterns involving missing data) were actually observed in the male sample, and 68 patterns (plus 19 patterns for missing data) appeared among the female sample. Although $\mathrm{L}^{2}$ fit statistics are common starting points to assess the absolute model fit of latent class models, this test is not very meaningful for our data, because with a sparse sample, the $\mathrm{L}^{2}$ fit statistic does not necessarily follow the asymptotic chi-square distribution required for such chisquare based tests.

Instead, relative fit measures offer more appropriate assessments of the adequacy of latent class models. These information criteria-based measures of the model's loglikelihood contrast model fit against parsimony. For different models, the Bayesian information criterion (BIC) and Akaike information criterion (AIC) are given in the online supplementary material (Table S.1). The BIC assigns a greater penalty to model complexity than the AIC, such that it tends to prefer smaller models. Acknowledging the complexity of our approach, we prefer the BIC selection, assuming there is a meaningful way to interpret the results from a qualitative standpoint. As a result, we adopt an eight-state model for both the male and female samples.

\section{Clustering Results}

Clustering individuals according to their personal living circumstances, according to the eight latent states and associated response probabilities, as we show in Table 1, produces response probabilities with great degrees of homogeneity and separation. To interpret the probabilities, we condense them into prototypical descriptions of the respective latent states (see Fig. 1 below and more detailed descriptions in supplementary Table S.2). Some caution is necessary when interpreting these latent states though, because the definitions of comparable male and female states are close but not exactly equivalent.

The most prevalent latent state for both genders describes a "classic" retiree, living in marriage with an also retired partner and children out of the house. Likely because of the early cut-off age for our sample, a working population accounts for the next largest latent state. In terms of gender differences, we note that the two models, each containing eight latent states, produce high-resolution views on different aspects of the life course. For women, widowhood and divorce are heterogeneous to such a degree that they warrant further segmentation; for men, segmentation is necessary for early retirement when wives continue to work. The statistically longer lifespan of women 


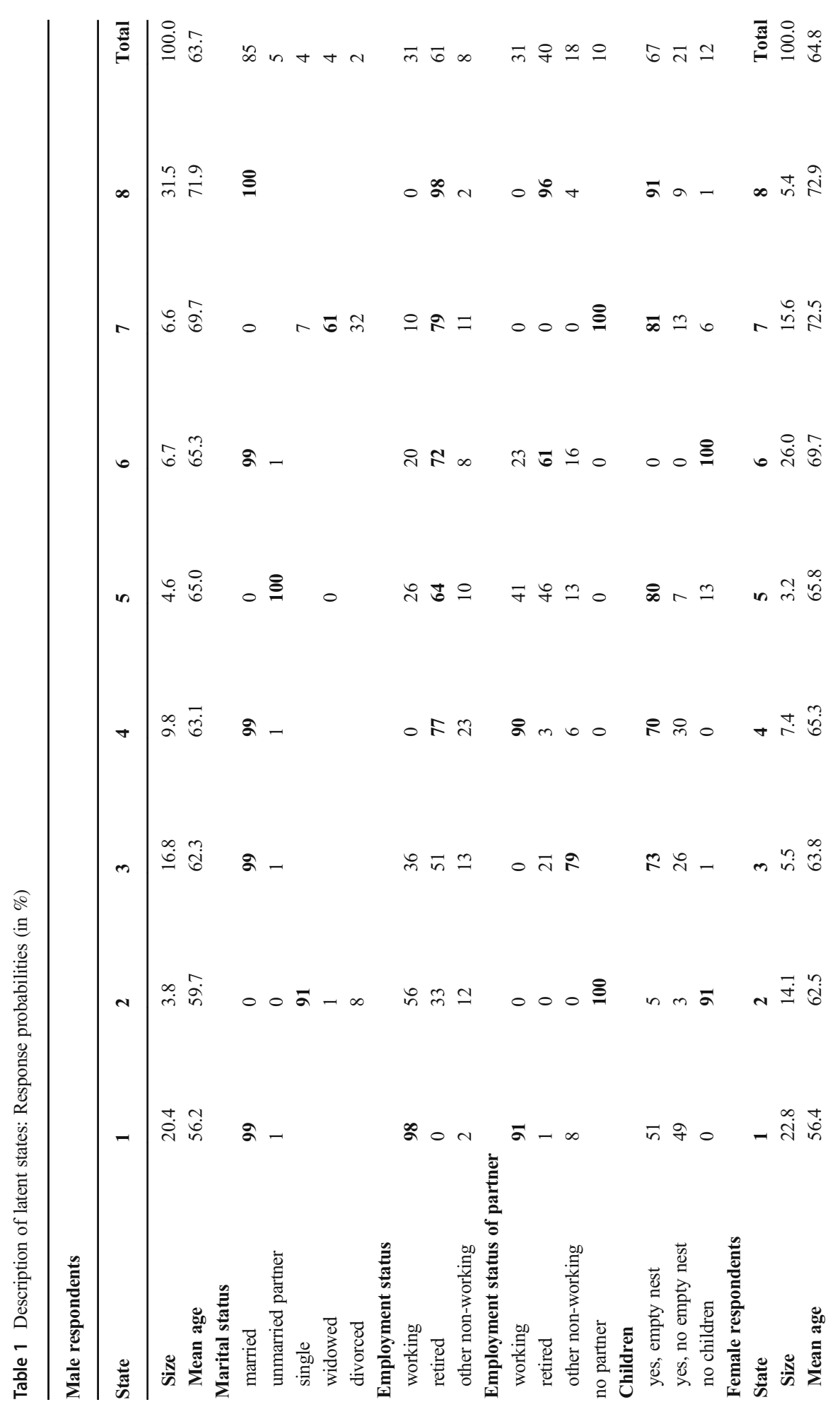




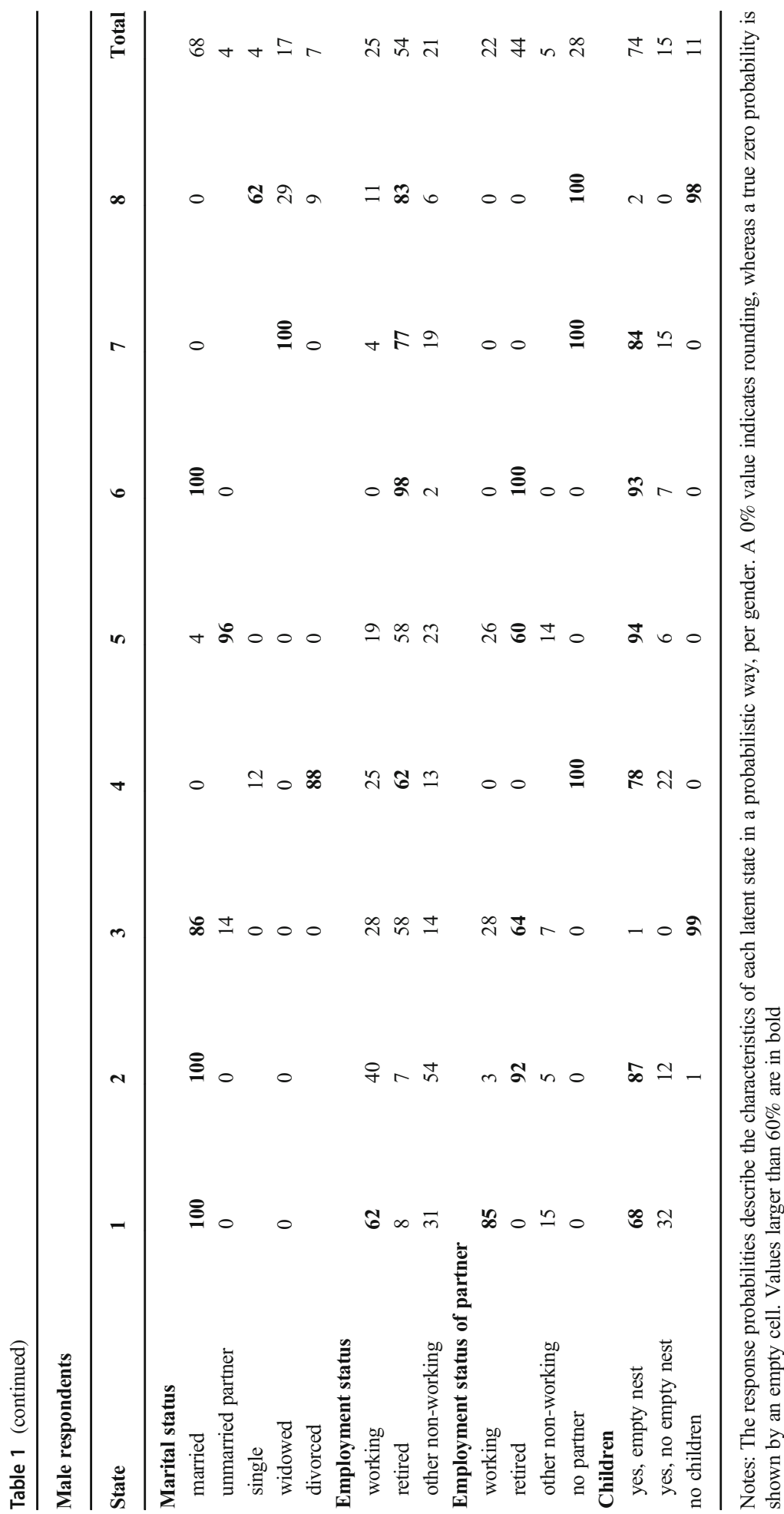




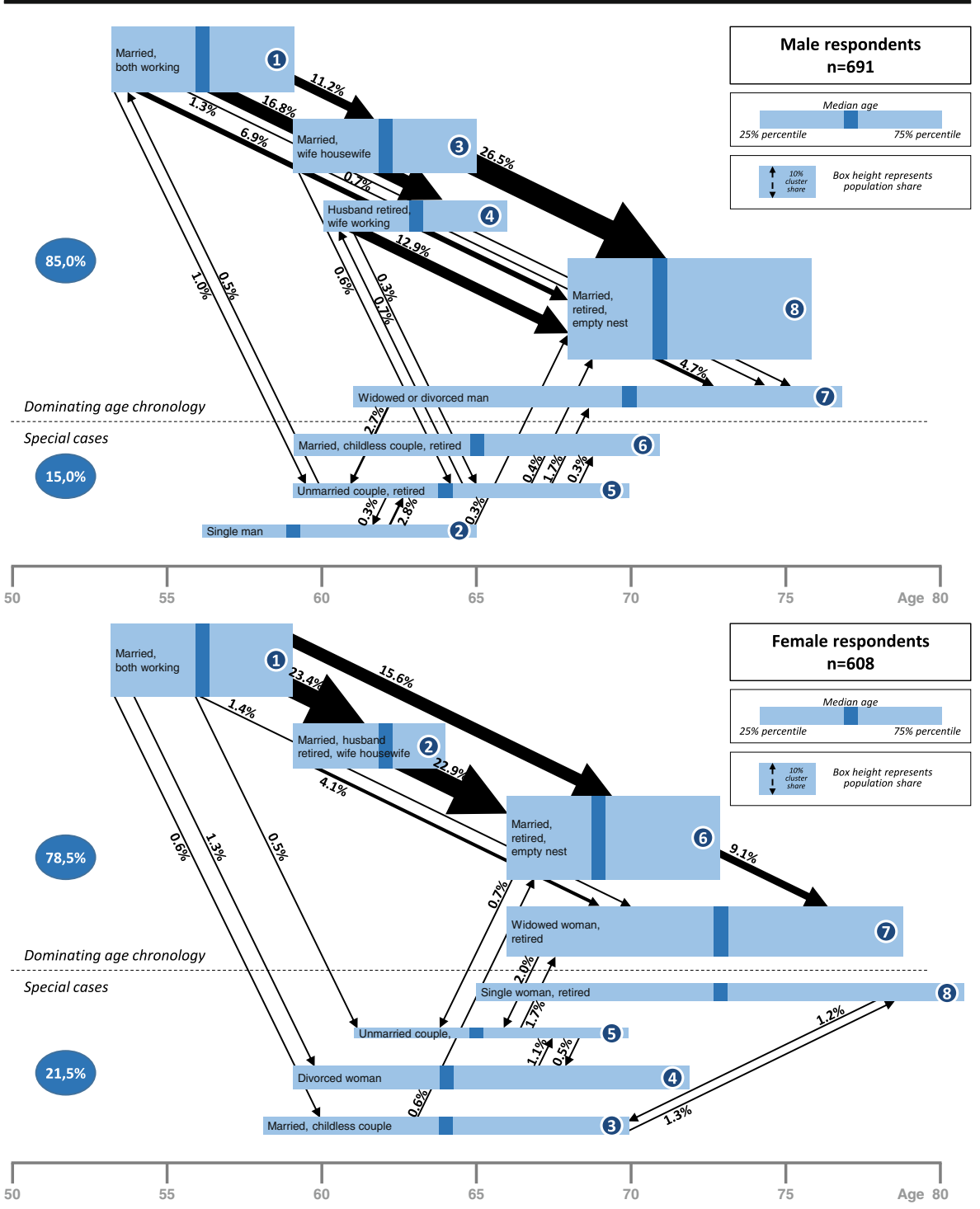

Fig. 1 Major latent state transitions for male and female respondents

with prolonged widowhood and the prevalence of housewives are both reflected in these latent states.

\section{Latent State Transitions over Time}

The probability of changing latent state membership, given the current state, is a key parameter that distinguishes a latent Markov model from more widely known latent class models. Table 2 exhibits those transition probabilities, such that we average the three individual transition probabilities across the four survey waves. In nearly all the states, the tables for both genders are dominated by the diagonal: More than half the 
people remain in the state to which they previously had been assigned. In general, the course through old age is more dynamic for men than for women, in that a greater total percentage of men in the sample actually experience some kind of transition. For example, $31.2 \%$ of the total surveyed population of men go through some kind of change in each of the three transitions points, but for women, the percentage is $29.7 \%$.

Considering changes in state membership, we note several meaningful observations. The largest states, describing a classic retired couple, are also the ones that most people transition to, after leaving other latent states. They are the final states for most participants in the model, especially men. The transition into widowhood from there is modelled only for a fraction of the population. In contrast, a few latent states seem mostly transitory, such that people enter and exit with a high turnover rate, such as states in which one or both partners are still working.

In Fig. 1 we depict the most important transitions; the percentages refer to the share of the total sample population that is affected, per gender. Both cases highlight a

Table 2 Latent state transitions

\begin{tabular}{|c|c|c|c|c|c|c|c|c|c|}
\hline \multicolumn{10}{|c|}{ Male respondents } \\
\hline \multirow{2}{*}{$\frac{\%}{\text { State(t) }}$} & \multicolumn{8}{|c|}{ State(t-1) } & \multirow{2}{*}{$\begin{array}{l}\% \text { (of total pop.) } \\
\text { coming to... }\end{array}$} \\
\hline & 1 & 2 & 3 & 4 & 5 & 6 & 7 & 8 & \\
\hline 1 & 51 & 0 & 0 & 0 & 3 & 0 & 0 & & 0.2 \\
\hline 2 & & 74 & & 1 & 2 & 0 & 0 & & 0.2 \\
\hline 3 & 15 & 0 & 52 & 0 & 0 & 0 & 0 & 0 & 3.8 \\
\hline 4 & 22 & 0 & 0 & 52 & 5 & 0 & 0 & 0 & 5.8 \\
\hline 5 & 1 & 23 & 1 & 0 & 71 & 0 & 16 & 0 & 2.4 \\
\hline 6 & 0 & 0 & 0 & 1 & 2 & 99 & 0 & & 0.2 \\
\hline 7 & 2 & 0 & 1 & 0 & 13 & 1 & 82 & 6 & 2.9 \\
\hline 8 & 9 & 3 & 46 & 46 & 3 & 0 & 1 & 94 & 15.8 \\
\hline going from... & 12.4 & 1.0 & 9.3 & 4.5 & 1.3 & 0.1 & 1.0 & 1.6 & 31.2 \\
\hline \multicolumn{10}{|c|}{ Female respondents } \\
\hline$\%$ & \multicolumn{8}{|c|}{ State(t-1) } & $\%$ (of total pop.) \\
\hline State(t) & 1 & 2 & 3 & 4 & 5 & 6 & 7 & 8 & coming to... \\
\hline 1 & 50 & 0 & 0 & 0 & 0 & 0 & 0 & 0 & 0.0 \\
\hline 2 & 27 & 42 & 0 & 0 & 0 & 0 & 0 & 0 & 7.8 \\
\hline 3 & 1 & 0 & 88 & 0 & 0 & 0 & 0 & 8 & 0.6 \\
\hline 4 & 1 & 0 & 0 & 92 & 6 & & 0 & 0 & 0.6 \\
\hline 5 & 1 & 0 & 1 & 5 & 74 & 1 & 5 & 0 & 1.5 \\
\hline 6 & 18 & 49 & 3 & 1 & 0 & 85 & 0 & 0 & 13.1 \\
\hline 7 & 2 & 9 & 0 & 1 & 20 & 14 & 95 & 0 & 5.5 \\
\hline 8 & & 0 & 7 & 1 & 0 & & 0 & 92 & 0.5 \\
\hline going from... & 14.3 & 9.0 & 0.7 & 0.6 & 0.7 & 3.3 & 0.7 & 0.4 & 29.7 \\
\hline
\end{tabular}

Notes: The transition tables show, as percentages, how many participants change class membership in subsequent waves, per gender. True zero not-rounded probabilities are indicated by empty fields. Values larger than $10 \%$ are in bold 
dominant chronology through old age, that is, the set of trajectories that the majority of the respondents go through. Most transitions follow a chronological structure, in that people move from states with lower median ages to states with higher median ages. In support of this chronological transition direction, in Table 2, we find that the probability densities below the diagonals are far higher than those above the diagonals. The figure also highlights the overall greater lifespan of women: By median age, clusters on the far end of the age spectrum, especially for widows, extend more than 2 years farther for women than for men.

In several special cases, personal circumstances do not follow the dominant succession though. For example, some transitions involve finding a new partner, such as when widows or single people initiate a new relationship. More than one-fifth of all women go through such special cases - markedly more than men, of whom only $15 \%$ experience circumstances that differ from the classic ageing chronology. When we look, however, at the permeability between dominant chronology and special cases it is striking to find that transitions from one group of clusters to the other happen more frequently in men $(8.2 \%)$ than in women $(7.4 \%)$. There is a slightly higher share of female transitions between such special cases, while men tend to transition back to a dominant chronology with a higher likelihood. Most striking in this regard are the single relationship status life states: while single males occupy this special state at a relatively younger age and sometimes find new partnerships (median age 59.7 years, no children, $3.1 \%$ percent finding new partnerships, cluster size 3.8\%) the life state of a single female is often the final state into advanced age, with less than half the likelihood to transition into new partnerships compared to men (median age 72.9 years, no children, $1.3 \%$ percent finding new partnerships, cluster size $5.4 \%$ ).

\section{Results of Step 2: Explaining Old-Age Well-Being}

\section{Linking Respondents and Additional Variables to the Life States}

The latent Markov model results present an empirically derived perspective on trajectories through old age for men and women. Another central contribution of our model is its flexible applicability to practical problem sets in various disciplines.

For the model output to be applied to such uses, we revert from a probabilistic view on ageing states, back to unambiguous individual states: The model in Eq. (1) describes latent states as probability distributions, based on different response patterns. It does not say anything about the definitive latent state membership of specific observed cases. Therefore, the model output needs to be translated into individual latent state memberships for each observation. We begin by calculating the so-called posterior probabilities for each observation, which describe the probability of belonging to a latent state, conditional on a given response pattern. In essence, it is the reverse of the probability for the responses, conditional on the latent states in Table 1. We assign a definitive latent state per time point to each response pattern in our male and female data sets, by choosing the latent state with the highest posterior probability (i.e. modal assignment).

The posterior probability of belonging to latent state $s$ given response pattern $y_{i}$ is calculated by applying the Bayes rule to the parameters estimated in the latent Markov model: 


$$
P\left(s \mid y_{i}\right)=\frac{P\left(y_{i} \mid s\right) P(s)}{P\left(y_{i}\right)}
$$

The posterior probabilities also allow for the flexible use of different sets of data. Theoretically, any observation from any data set can be classified into one of the eight states of our latent Markov model, provided it contains the four indicator variables (missing data for single cells is allowed but makes the results less reliable).

In our case, having applied the latent Markov model to only a fraction of the representative survey data - namely, those observations for which at least two transitions exist in the data - the posterior probabilities allow us to revert back to the full sample of people aged 50 years and older. Once we apply modal latent state assignments to each of the observations in the representative sample of people at least 50 years of age, we arrive at a new sample of 18,619 respondents, including 9576 (51.4\%) men and 9043 (48.6\%) women. The sampling weights are applied throughout the course of the analysis.

To analyse how well the latent life states can explain well-being, we select additional variables from the DEAS survey and link them to the life states, using the posterior probabilities as described in Table 3 (retaining the distinction between the dominant age chronology and special cases). We select household income (in Euro) because income is typically associated with well-being (Mayer et al., 1999). We also select measures for general life satisfaction (Pavot \& Diener, 1993), loneliness (De Jong Gierveld \& Van Tilburg, 2006), and depression (Hautzinger \& Bailer, 1993). These are generated composite variables included in the DEAS dataset.

Our descriptive results support the notion of a strong heterogeneity in advanced age. First, a general age effect is visible only for household income, which tends to decrease with advancing age. This is most likely explained by the changes in household composition as well as the onset of retirement as people get older. Interestingly, the three well-being variables do not exhibit a strong age component. Life satisfaction is highest in the retirement couple constellation (plus in the housewife state for women) and lowest in the states of widowhood and single for men as well as in divorce for women. In most cases, the couple constellations show an above average life satisfaction while the single state rank mostly below average. Similar observations can be made for the depression score: Widows, divorcé(e)s, and female single states show the highest scores here. Loneliness, then again, is lowest for retired couples and unmarried couples (both under a female perspective). Negative outliers are male widows and divorcés as well as singles, who all show high scores.

Interestingly, while some of the lowest income households-widows, divorcé(e)s, and singles - have a strong risk of low well-being, household income alone cannot explain all the differences in the well-being scores. When comparing the dominant and largely chronological life states with the less common special cases that encompass a wider range of age, we find that couples in the special cases have higher incomes than "normal" retirees, but lower life satisfaction scores. When comparing life satisfaction in male and female life courses, only depression shows a strong overall divergence between men and women, who are on average higher on that score. For the two other well-being variables, the average readings are about equal for men and women. In sum, our findings support the notion that lonesome living circumstances and reclusive lifestyles, rather than limited financial possibilities, often go hand in hand, with little aspiration to follow the societal promise of successful ageing. 


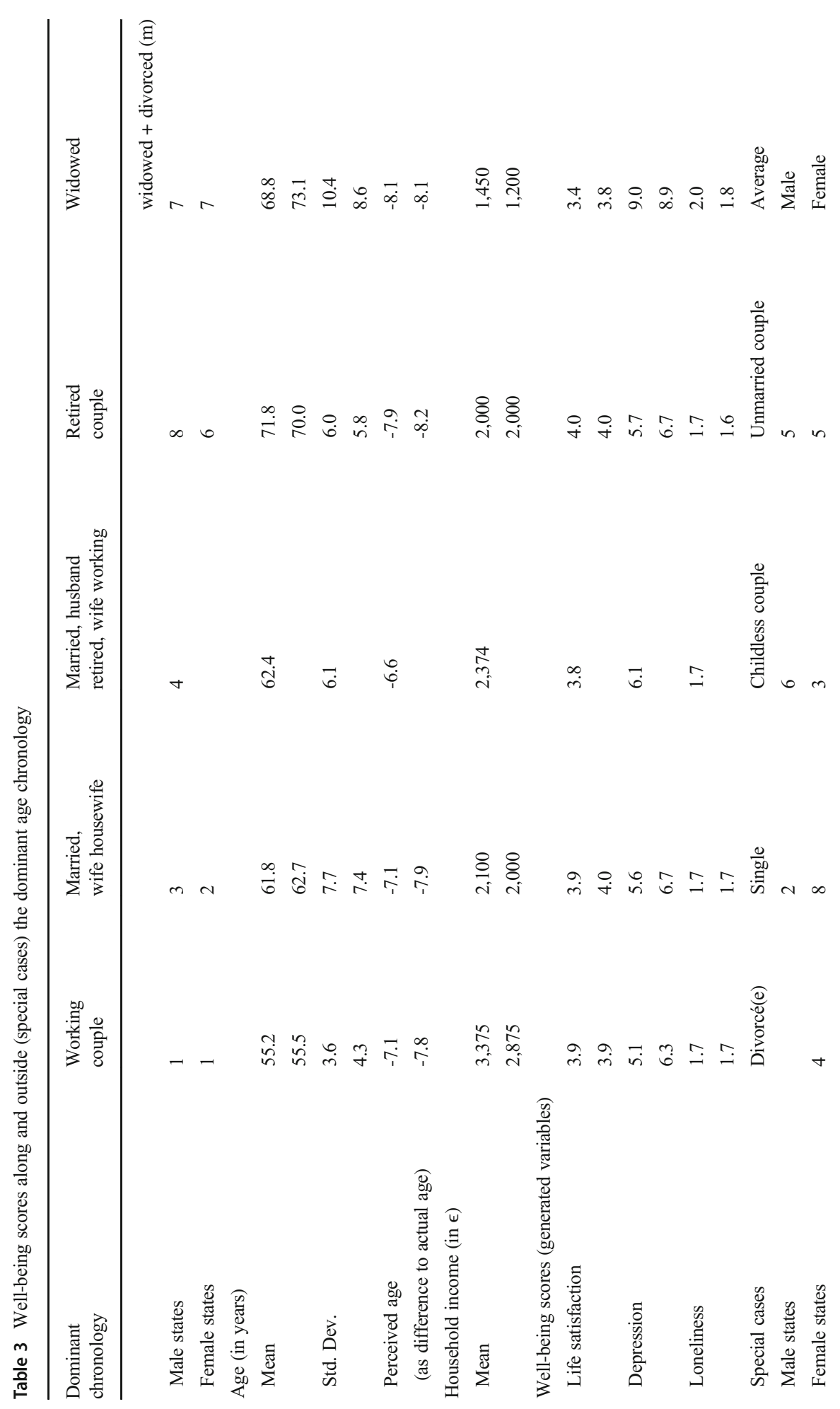


लुं

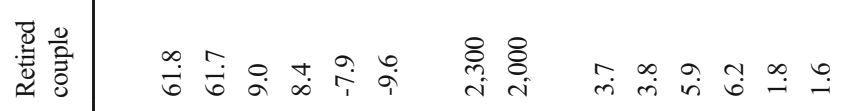

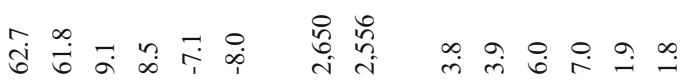

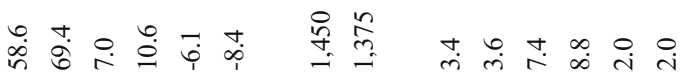

$\frac{\stackrel{0}{3} 0}{3}$

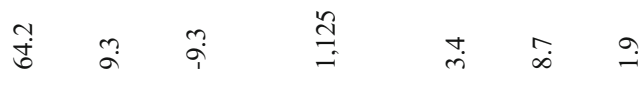

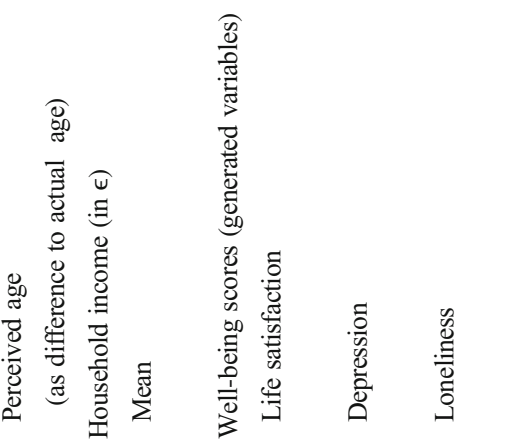




\section{Predictive Accuracy against Benchmark Models}

We now demonstrate the ability of our model to predict and forecast well-being variables better than chronological age alone, and better than common APC models that additionally include cohort and period effects.

To predict well-being of a participant using the life course model, we employ a dummy regression, where each latent life state acts as a regressor predicting the wellbeing variables of interest. Again we choose the full survey sample and pick the first participation wave of each observed participant to train our regression model. Depending on the outcome variable and the amount of missing observations, between $54 \%$ and $65 \%$ of the observations represent training data. With this calibrated regression model, for each participant, we predict up to three future observations (based on the life state trajectory as described by our Markov model) for the outcome variables and compare the predictions against actually observed values from the survey when those values are available, i.e. not missing.

The results of these comparisons are in Table 4, describing the predicted fit based on holdout data of several well-being variables as well as of household income. As a measure we use a weighted variant of the mean absolute percentage error (MAPE). This weighted fit measure is more robust than the widely used unweighted MAPE, which lacks robustness in the context of very small or zero observed values and also puts a stronger weight on negative $\left(y_{t}<\hat{y}_{t}\right)$ as opposed to positive errors (Hyndman \& Koehler, 2006). The weighted MAPE still measures accuracy as a percentage, such that smaller values show a better fit. However, the percentage values are not directly comparable across different dependent variables. The weighted MAPE is given by the following equation:

$$
w M A P E=\frac{\sum_{i=1}^{n}\left|\frac{y_{i}-\widehat{y}_{i}}{\widehat{y}_{i}}\right| \widehat{y}_{i}}{\sum_{i=1}^{n} y_{i}}
$$

We benchmark the predictions based on the latent states against three other prediction models. The first employs continuous chronological age as a regressor. The second benchmark model uses age dummy variables for every five years, resulting in a number of regression coefficients equivalent to the latent state model - that is, eight age dummy variables and eight latent states. In a third model, we fit a basic APC model that uses continuous age, cohort dummy variables for every five birth-years beginning in 1915, and four period dummy variables for each of the four survey waves as regressors. As we code period effects using the interview years of the four survey waves, which have an offset and spacing different from the age and cohort variables, we avoid the wellknown identification problem inherent in most APC models (Bell \& Jones, 2013; Kupper et al., 1985).

The results in Table 4 produce three main conclusions:

(1) Predictions based on latent life states match or outperform well-being predictions that rely purely on age or that rely on age, cohort, and period effects. 


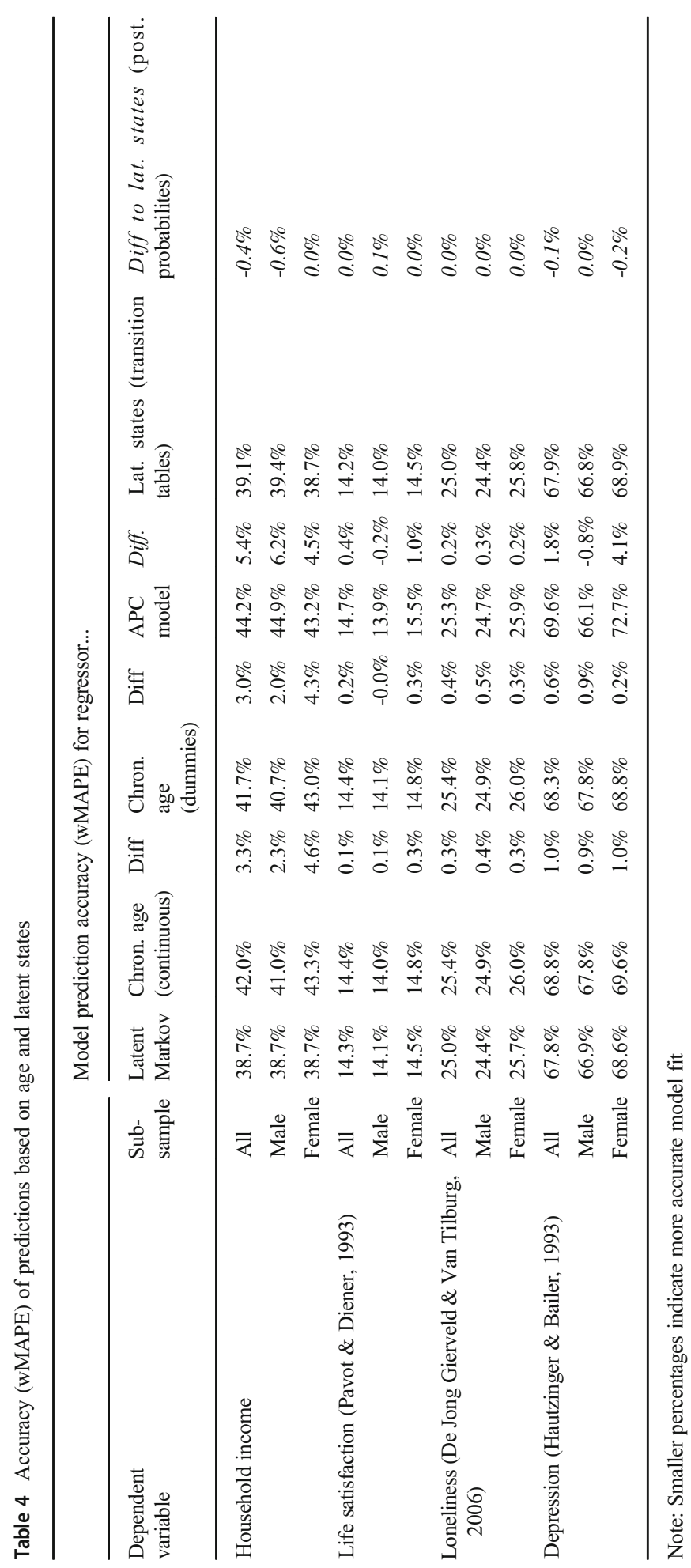


(2) Only life satisfaction of men is slightly better predicted when using either of the benchmark models, and only for the depression score of men, the APC model performs best. However, in each of these cases the wMAPE differences are very close, below one percentage point, whereas the latent life state model outperforms other cases by several percentage points. This demonstrates the robust performance of the latent life state model.

(3) The dummy age model nearly consistently outperforms the linear age model; this is not surprising as it is the more complex model. The even more complex APC model, however, lags both age models in predicting household income and life satisfaction with inconsistent results for the other two variables.

Finally, we assess the validity of the transition tables produced by the latent Markov model, to use for forecasting. That is, we compare the first prediction model based on known latent states, in the form of posterior probabilities, with a prediction model in which we extrapolate latent states using transition tables. This latter model reflects a situation in which future latent states are unknown. We compare the prediction results for the same well-being variables as before. The differences are very small with the latent states from posterior probabilities, usually giving slightly better predictions. We thus conclude that the transition tables predict future latent states reasonably well.

\section{Discussion}

Our results offer strong evidence that men and women age differently when it comes to ageing trajectories and lengths spent in different life states and social roles. While a "normal" married, retired couple still dominates through much of the chronological age span, more men than women follow a classic chronology through old age and avoid less conventional age arrangements, such as being single or divorce. But this popular view of old-age life as a couple in a household, such that one partner, usually the woman, eventually becomes a widow, represents only part of the picture. Many life changes commonly associated with middle age - divorce, finding a new partner, living together without marriage - also happen in advanced age. Beyond that, we find evidence that if and when men drop out of the classic chronology, they subsequently show more transitions back into classic marriage than women; especially single men seem less willing to accept their status for the rest of their lives as opposed to single women. As to the causations at play here, more research will be needed into the different age structures of both genders as well as their motives for transitioning into other, e.g. non-single states.

The evidence of a different ageing trajectory becomes more tangible when we add additional variables on well-being. The degree to which life transitions and gender affect a number of well-being scores varies markedly. We find that couple households exhibit a significantly higher life satisfaction than people living alone. This higher life satisfaction also correlates with higher household incomes (Pinquart \& Sörensen, 2000), but when comparing couple life states, those with higher incomes (unmarried couples, childless couples) seem slightly less satisfied than the dominant state of a retired couple. While some transitions in old age can entail significant changes in social conditions, such as the death of a spouse or finding a new partner, we observe that the most prevalent transitions happen between socially homogeneous states. 
Though our model cannot entirely explain the causalities at play here there are hints that higher incomes are only one puzzle piece to a high life satisfaction; comparing a working couple with very high incomes and a retired couple with a medium household income we find the latter is generally more satisfied. Also, female widows are generally more satisfied than divorcées - at roughly the same income. We find that high depression and loneliness scores roughly go along with lower life satisfaction- the extent to which this is true differs, however. Also, women tend to show higher depression but slightly lower loneliness scores. While our model only allows for cautious assumptions on cause and effect there is some evidence that the causalities between our well-being variables may run in various directions and may in fact be reciprocal (Cacioppo et al., 2006; Prince et al., 1997). Aside from causalities, the strong divergence in household incomes indicates an inherent social inequality among the older population. The literature underlines this has implications for a wide range of living circumstances, from health to happiness (Mayer et al., 1999).

Most special cases as highlighted by Fig. 1 are usually associated with lower wellbeing scores than the dominating pathway through old age; especially singles - both male and female - exhibit above average loneliness and depression scores. Only in widows is the depression metric higher. This would support the notion that partnerships are a strong mediator to better well-being. On the positive side, as Fig. 1 shows, finding a new partner and even (first or renewed) marriage in advanced age are not uncommon. As the reverse arrows indicate, such a new partnership is often associated with household setting that correlates with lower median age than before-following this train of thought, (mental) ageing is to some extent reversed, which may also explain an improvement in well-being scores.

Using these results, marketing managers may end up with different old-age consumer target groups based on whether they follow a volume or value strategy. A marketing strategy that seeks to maximise sales volumes must focus on segments with a large number of potential buyers. Such a strategy is unlikely to highlight a product's value and the marketing message will not primarily appeal to the consumer's wellbeing, values and attitudes. The contrary is true for a strategy that puts a product's value first: Here, the marketing message will be much more centered around the characteristics of the consumer - ideally, the consumer identifies with a product as he feels it reflects his attitude on life. People that are susceptible to such messages usually need a positive outlook on at least some aspects of their life.

While the life states along the dominant age chronology account for the largest percentage of the consumer population, some smaller special cases offer higher incomes than the majority of retirees. To dive deeper here, our model can be easily amended to serve as a framework for exploring the customer value of different old-age groups (Payne \& Holt, 2001). Policymakers, in contrast, may focus on the growing number of single life states, as these struggle most with loneliness, or depression.

Our life course model consistently performs on par or better than models of chronological age as well as APC models to predict the outcomes in old-age wellbeing. However, it should be noted that the present model is a life course model purely based on social institutions; it makes no discrimination with regard to age, treating a 50 year old consumer the same as a 65 year old consumer if they end up in the same life state. It is conceivable that some of our life states potentially interact with chronological age such that chronological age may reflect physical capacities and health. As other 
research shows, some age-related phenomena are prone to the effects of life states, but others follow chronological age, likely due to a general deterioration in health, whether physiological or psychological (Mayer et al., 1999). Future models of age as a process could thus consider chronological age as well as life circumstances, if only as proxies for other unobserved variables. For example, future inquiries could use linear regressions on age in each of the clusters, to determine how strong age effects are in different life circumstances. Going forward, also the gender differences and gender inequalities of ageing trajectories that our approach exposes may be further explored to reveal less obvious gender aspects of ageing that may be hidden within "norms, practices and values" (Broadbridge \& Simpson, 2011, p. 478).

Finally, our model setup could be amended to include cohort and period effects in order to complement APC models (Bengtson \& Allen, 1993; Glenn, 2003). Instead of aggregating life states and transition probabilities across several time points, the model could be used to follow different birth cohorts rather than two gender groups. For such a zeitgeist view, data spanning a period longer than the 15 years of our sample ideally would be available.

Supplementary Information The online version contains supplementary material available at https://doi.org/ 10.1007/s11482-021-09934-6.

Acknowledgements We thank the Research Data Centre of the German Centre of Gerontology (DZA) for the provision of the DEAS data, without which this research would not have been possible.

Funding Open Access funding enabled and organized by Projekt DEAL. This work was supported by a $\mathrm{PhD}$ scholarship from the Viadrina Center B/Orders in Motion.

\section{Declarations}

Conflict of Interest The authors declare that there are no conflicts of interest.

Open Access This article is licensed under a Creative Commons Attribution 4.0 International License, which permits use, sharing, adaptation, distribution and reproduction in any medium or format, as long as you give appropriate credit to the original author(s) and the source, provide a link to the Creative Commons licence, and indicate if changes were made. The images or other third party material in this article are included in the article's Creative Commons licence, unless indicated otherwise in a credit line to the material. If material is not included in the article's Creative Commons licence and your intended use is not permitted by statutory regulation or exceeds the permitted use, you will need to obtain permission directly from the copyright holder. To view a copy of this licence, visit http://creativecommons.org/licenses/by/4.0/.

\section{References}

Alwin, D. F. (2012). 'Integrating varieties of life course concepts', The Journals of Gerontology Series B: Psychological Sciences and Social Sciences, 67B, pp. 206-220, doi: https://doi.org/10.1093/geronb/ gbr146.

Arber, S. \& Cooper, H. (1999). 'Gender differences in health in later life: The new paradox?', Social Science \& Medicine, 48, pp. 61-76, doi: https://doi.org/10.1016/S0277-9536(98)00289-5.

Bagozzi, R., Gopinath, M. \& Nyer, P. (1999). 'The role of emotions in marketing', Journal of the Academy of Marketing Science, 27, pp. 184-206, doi: https://doi.org/10.1177/0092070399272005.

Baltes, M. M. \& Carstensen, L. L. (1996). 'The process of successful ageing', Ageing \& Society, 16, pp. 397422, doi: https://doi.org/10.1017/S0144686X00003603. 
Baltes, P. B. \& Mayer, K. U. (2001). The Berlin aging study: Aging from 70 to 100. Cambridge University Press.

Bell, A. \& Jones, K. (2013). 'The impossibility of separating age, period and cohort effects', Social Science \& Medicine, 93, pp. 163-165, doi: https://doi.org/10.1016/j.socscimed.2013.04.029.

Bengtson, V. L. \& Allen, K. R. (1993). 'The life course perspective applied to families over time'. In P. Boss, W. J. Doherty, R. LaRossa, W. R. Schumm and S. K. Steinmetz (eds.), 'Sourcebook of family theories and methods: A contextual approach', pp. 469-504, Springer US.

Billari, F. C. (2009). 'The life course is coming of age', Advances in Life Course Research, 14, pp. 83-86, doi: https://doi.org/10.1016/j.alcr.2009.10.001

Bloom, D. E. (2011). '7 billion and counting', Science, 333, pp. 562-569, doi: https://doi.org/10.1126/science. 1209290.

Bowling, A. \& Dieppe, P. (2005). 'What is successful ageing and who should define it?', BMJ, 331, pp. 15481551, doi: https://doi.org/10.1136/bmj.331.7531.1548.

Bowling, A. \& Iliffe, S. (2006). 'Which model of successful ageing should be used? Baseline findings from a British longitudinal survey of ageing', Age and Ageing, 35, pp. 607-614, doi: https://doi.org/10.1093/ ageing/afl100.

Broadbridge, A. \& Simpson, R. (2011). '25 years on: Reflecting on the past and looking to the future in gender and management research', British Journal of Management, 22, pp. 470-483, doi: https://doi.org/10.1111/ j.1467-8551.2011.00758.x.

Burton, D. (2005). 'Marketing theory matters', British Journal of Management, 16, pp. 5-18, doi: https://doi. org/10.1111/j.1467-8551.2005.00432.x.

Butz, W. P. \& Torrey, B. B. (2006). `Some Frontiers in social sciences', Science, 312, pp. 1898-1900, doi: https://doi.org/10.1126/science.1130121.

Cacioppo, J. T., Hughes, M. E., Waite, L. J., Hawkley, L. C. \& Thisted, R. A. (2006). 'Loneliness as a specific risk factor for depressive symptoms: Cross-sectional and longitudinal analyses.', Psychology and Aging, 21, pp. 140-151.

Collins, L. M. \& Lanza, S. T. (2010). Latent class and latent transition analysis: With applications in the social, behavioral, and health sciences, Wiley.

Crimmins, E. M. \& Beltrán-Sánchez, H. (2011). 'Mortality and morbidity trends: Is there compression of morbidity?', The Journals of Gerontology Series B: Psychological Sciences and Social Sciences, 66B, pp. 75-86, doi: https://doi.org/10.1093/geronb/gbq088.

Dannefer, D. (2003). Cumulative advantage/disadvantage and the life course: Cross-fertilizing age and social science theory. The Journals of Gerontology Series B: Psychological Sciences and Social Sciences 58(6): S327-S337.

De Jong Gierveld, J. \& Van Tilburg, T. (2006). 'A 6-item scale for overall, emotional, and social loneliness confirmatory tests on survey data', Research on Aging, 28, pp. 582-598, doi: https://doi.org/10.1177/ 0164027506289723.

Diener, E. (1984). 'Subjective well-being', Psychological Bulletin, 95, pp. 542-575, doi: https://doi.org/10. 1037/0033-2909.95.3.542.

Diener, E., Suh, E. M., Lucas, R. E. \& Smith, H. L. (1999). 'Subjective well-being: Three decades of progress', Psychological Bulletin, 125, pp. 276-302, doi: https://doi.org/10.1037/0033-2909.125.2.276.

Du, R. Y. \& Kamakura, W. A. (2006). 'Household life cycles and lifestyles in the United States', Journal of Marketing Research, 43, pp. 121-132.

Elder, G. H. (1985). 'Perspectives on the life course'. In G. H. Elder (ed.), 'Life course dynamics: Trajectories and transitions, 1968-1980', pp. 23-49, Cornell University Press.

Engstler, H. \& Schmiade, N. (2013). 'The German ageing survey (DEAS) - A longitudinal and time-series study of people in the second half of life', Schmollers Jahrbuch, 133, pp. 97-107, doi: https://doi.org/10. 3790/schm.133.1.97.

Espenshade, T. J. (1986). 'Markov chain models of marital event histories'. In D. I. Kertzer and Z. Smith Blau (eds.), 'Current Perspectives on Aging and the Life Cycle: Family Relations in Life Course Perspective', vol. 2, pp. 73-106, JAI Press.

Fry, P. S. (1992). 'Major social theories of aging and their implications for counseling concepts and practice: A critical review', The Counseling Psychologist, 20, pp. 246-329, doi: https://doi.org/10.1177/ 0011000092202002.

Ganglmair-Wooliscroft, A. \& Lawson, R. (2012). 'Subjective wellbeing and its influence on consumer sentiment towards marketing: A New Zealand example', Journal of Happiness Studies, 13, pp. 149166, doi: https://doi.org/10.1007/s10902-011-9255-9. 
Glenn, N. D. (2003). `Distinguishing age, period, and cohort effects'. In J. T. Mortimer and M. J. Shanahan (eds.), 'Handbook of the Life Course', Handbooks of Sociology and Social Research, pp. 465-476, Springer US.

Gold, C. H., Malmberg, B., McClearn, G. E., Pedersen, N. L. \& Berg, S. (2002). 'Gender and health: A study of older unlike-sex twins', The Journals of Gerontology Series B: Psychological Sciences and Social Sciences, 57B, pp. S168-S176, doi: https://doi.org/10.1093/geronb/57.3.S168.

Gorman, B. K. \& Read, J. G. (2007). 'Why men die younger than women', Geriatrics and Aging, 10, pp. 182191.

Hautzinger, M. \& Bailer, M. (1993). ADS-Allgemeine Depressions-Skala, Beltz.

Hendricks, J. (2012). 'Considering life course concepts', The Journals of Gerontology Series B: Psychological Sciences and Social Sciences, 67B, pp. 226-231, doi: https://doi.org/10.1093/geronb/gbr147.

Hyndman, R. J. \& Koehler, A. B. (2006). 'Another look at measures of forecast accuracy', International Journal of Forecasting, 22, pp. 679-688, doi: https://doi.org/10.1016/j.ijforecast.2006.03.001.

Kohlbacher, F. \& Hang, C. (2011). 'Applying the disruptive innovation framework to the silver market', Ageing International, 36, pp. 82-101, doi: https://doi.org/10.1007/s12126-010-9076-X.

Kryspin-Exner, I., Lamplmayr, E. \& Felnhofer, A. (2011). 'Geropsychology: The gender gap in human aging - A mini-review', Gerontology, 57, pp. 539-548, doi: https://doi.org/10.1159/000323154.

Kupper, L. L., Janis, J. M., Karmous, A. \& Greenberg, B. G. (1985). `Statistical age-period-cohort analysis: A review and critique', Journal of Chronic Diseases, 38, pp. 811-830, doi: https://doi.org/10.1016/00219681(85)90105-5.

Lowsky, D. J., Olshansky, S. J., Bhattacharya, J. \& Goldman, D. P. (2013). 'Heterogeneity in healthy aging', The Journals of Gerontology Series A: Biological Sciences and Medical Sciences, pp. 640-649, doi: https://doi.org/10.1093/gerona/glt162, Heterogeneity in Healthy Aging.

Lucas, R. E., Diener, E. \& Suh, E. M. (1996). 'Discriminant validity of wellbeing measures', Journal of Personality and Social Psychology, 71, pp. 616-628, doi: https://doi.org/10.1037/0022-3514.71.3.616.

Macintyre, S., Hunt, K. \& Sweeting, H. (1996). 'Gender differences in health: Are things really as simple as they seem?', Social Science \& Medicine, 42, pp. 617-624, doi: https://doi.org/10.1016/0277-9536(95) 00335-5.

Macmillan, R. \& Eliason, S. R. (2003). 'Characterizing the life course as role configurations and pathways'. In J. T. Mortimer and M. J. Shanahan (eds.), 'Handbook of the Life Course', Handbooks of Sociology and Social Research, pp. 529-554, Springer US.

Mathur, A., Moschis, G. P. \& Lee, E. (2003). 'Life events and brand preference changes', Journal of Consumer Behaviour, 3, pp. 129-141, doi: https://doi.org/10.1002/cb.128.

Mayer, K. U. (2009). 'New directions in life course research', Annual Review of Sociology, 35, pp. 413-433, doi: https://doi.org/10.1146/annurev.soc.34.040507.134619.

Mayer, K. U., Maas, I. \& Wagner, M. (1999). 'Socioeconomic conditions and social inequalities in old age'. In P. B. Baltes and K. U. Mayer (eds.), 'The Berlin aging study: Aging from 70 to 100 ', pp. 227-55, Cambridge University Press.

Moen, P. (2003). 'Midcourse'. In J. T. Mortimer and M. J. Shanahan (eds.), 'Handbook of the Life Course', Handbooks of Sociology and Social Research, pp. 269-291, Springer US

Moschis, G. P. (2007). 'Life course perspectives on consumer behavior', Journal of the Academy of Marketing Science, 35, pp. 295-307, doi: https://doi.org/10.1007/s11747-007-0027-3.

Moschis, G. P. (2012). 'Consumer behavior in later life: Current knowledge, issues, and new directions for research', Psychology and Marketing, 29, pp. 57-75, doi: https://doi.org/10.1002/mar.20504.

Moschis, G. P., Lee, E. \& Mathur, A. (1997). 'Targeting the mature market: Opportunities and challenges', Journal of Consumer Marketing, 14, pp. 282-293, doi: https://doi.org/10.1108/07363769710188536.

Pak, C. \& Kambil, A. (2006). 'Over 50 and ready to shop: Serving the aging consumer', Journal of Business Strategy, 27, pp. 18-28, doi: https://doi.org/10.1108/02756660610710319.

Pannhorst, M. \& Dost, F. (2019). 'Marketing innovations to old-age consumers: A dynamic bass model for different life stages', Technological Forecasting and Social Change, 140, pp. 315-327, doi: https://doi.org/ 10.1016/j.techfore.2018.12.022.

Pavot, W. \& Diener, E. (1993). 'Review of the satisfaction with life scale', Psychological Assessment, 5, pp. 164-172, doi: https://doi.org/10.1037/1040-3590.5.2.164.

Payne, A. \& Holt, S. (2001). 'diagnosing customer value: Integrating the value process and relationship marketing', British Journal of Management, 12, pp. 159-182, doi: https://doi.org/10.1111/1467-8551. 00192.

Perrig-Chiello, P. \& Hutchison, S. (2010). 'Health and well-being in old age: The pertinence of a gender mainstreaming approach in research', Gerontology, 56, pp. 208-213, doi: https://doi.org/10.1159/ 000235813. 
Pinquart, M. \& Sörensen, S. (2000). 'Influences of socioeconomic status, social network, and competence on subjective well-being in later life: A meta-analysis', Psychology and Aging, 15, pp. 187-224, doi: https:// doi.org/10.1037/0882-7974.15.2.187.

Prince, M. J., Harwood, R. H., Blizard, R. A., Thomas, A. \& Mann, A. H. (1997). 'Social support deficits, loneliness and life events as risk factors for depression in old age. The gospel oak project VI', Psychological Medicine, 27, pp. 323-332.

Reitzes, D. C. \& Mutran, E. J. (2004). 'The transition to retirement: Stages and factors that influence retirement adjustment', The International Journal of Aging and Human Development, 59, pp. 63-84, doi: https://doi.org/10.2190/NYPP-RFFP-5RFK-8EB8.

Rentz, J. O., Reynolds, F. D. \& Stout, R. G. (1983). `Analyzing changing consumption patterns with cohort analysis', Journal of Marketing Research, 20, pp. 12-20, doi: https://doi.org/10.2307/3151407.

Rowe, J. W. \& Kahn, R. L. (1987). 'Human aging: Usual and successful', Science, 237(4811), pp. 143-149.

Schaninger, C. M. \& Danko, W. D. (1993). `A conceptual and empirical comparison of alternative household life cycle models', Journal of Consumer Research, 19, pp. 580-594.

Settersten, R. A., Jr. \& Mayer, K. U. (1997). 'The measurement of age, age structuring, and the life course', Annual Review of Sociology, 23, pp. 233-261.

Silvera, D. H., Lavack, A. M. \& Kropp, F. (2008). 'Impulse buying: The role of affect, social influence, and subjective wellbeing', Journal of Consumer Marketing, 25, pp. 23-33, doi: https://doi.org/10.1108/ 07363760810845381.

Sudbury, L. \& P. Simcock (2009). 'A multivariate segmentation model of senior consumers', Journal of Consumer Marketing, 26, pp. 251-262, doi: https://doi.org/10.1108/07363760910965855.

Thompson, N. J. \& Thompson, K. E. (2009). 'Can marketing practice keep up with Europe's ageing population?', European Journal of Marketing, 43, pp. 1281-1288, doi: https://doi.org/10.1108/ 03090560910989885.

Vermunt, J. K. \& Magidson, J. (2013). 'Technical guide for latent GOLD 5.0: Basic, advanced, and syntax', Statistical Innovations Inc.

Visser, I., Raijmakers, M. E. J. and Maas, H. L. J. (2009). 'Hidden Markov Models for Individual Time Series'. In J. Valsiner, P. C. M. Molenaar, M. C. D. P. Lyra and N. Chaudhary (eds.), 'Dynamic process methodology in the social and developmental sciences', pp. 269-289, Springer US.

Wagner, J. \& Hanna, S. (1983). 'The effectiveness of family life cycle variables in consumer expenditure research', Journal of Consumer Research, 10, pp. 281-291

Walker, P. (2018). 'May appoints minister to tackle loneliness issues raised by Jo Cox', The Guardian. 16 January 2018. Available from: www.theguardian.com/society/2018/jan/16/may-appoints-minister-tackleloneliness-issues-raised-jo-cox. Accessed 11 September 2019

Williams, K. C. \& Page, R. A. (2011). 'Marketing to the generations', Journal of Behavioral Studies in Business, 3, pp. 37-52.

Wilson, W. R. (1967). 'Correlates of avowed happiness', Psychological Bulletin, 67, pp. 294-306, doi: https:// doi.org/10.1037/h0024431.

Yoon, C., Cole, C. A. \& Lee, M. P. (2009). 'Consumer decision making and aging: Current knowledge and future directions', Journal of Consumer Psychology, 19, pp. 2-16, doi: https://doi.org/10.1016/j.jcps.2008. 12.002 .

Publisher's Note Springer Nature remains neutral with regard to jurisdictional claims in published maps and institutional affiliations.

Matthias Pannhorst is a doctoral researcher at the European University Viadrina. His research interests focus on the implications of an ageing society on consumer marketing with an emphasis on quantitative analyses and forecasting through empirical models; public policy responses to shifting demographic weights; as well as the macro impact of global aging on institutions like social security and welfare systems.

Florian Dost is a Professor for Marketing at the Brandenburg University of Technology. His research revolves around forecasting complex systems; macro consequences of aggregate marketing phenomena; consumer willingness to pay under uncertainty; and word-of-mouth marketing. He is also frequently consulting on market research projects and collaborative forms of marketing. 